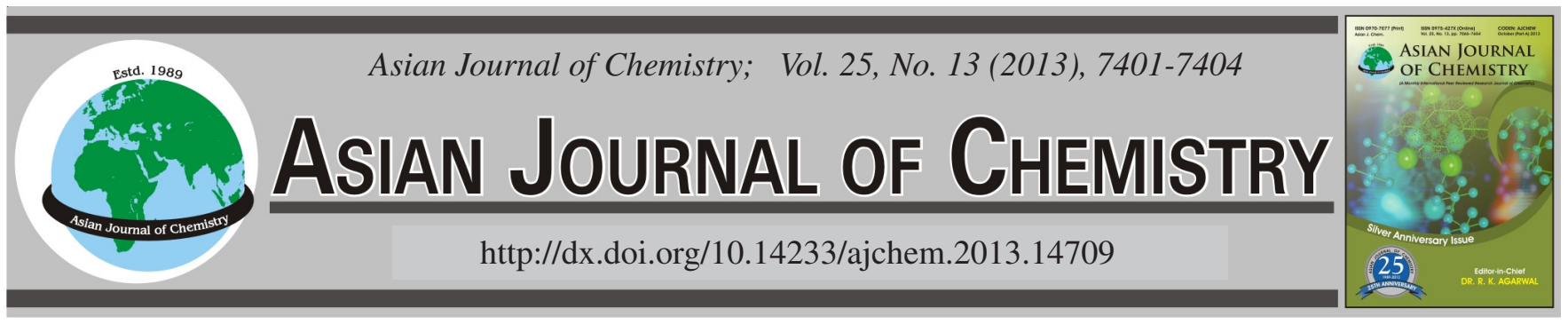

\title{
Antioxidant Effect of Apple Polyphenols by Flow Injection Chemiluminescence
}

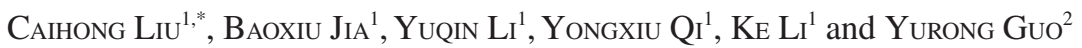

${ }^{1}$ College of Pharmaceutical, Taishan Medical University, Tai'an 271016, P.R. China

${ }^{2}$ College of Food Engineering and Nutritional Science, Xi'an 710000, P.R. China

*Corresponding author: E-mail: liuch7688@163.com

The antioxidant effect of apple polyphenols extract in vitro was determinated by flow injection analysis chemiluminescence (FIA-CL). The ascorbic acid was used as positive control. Inhibition by apple polyphenols extract or ascorbic acid of the steady chemiluminescence emissions of various oxidants with luminol was measured. $\mathrm{IC}_{50}$ values of apple polyphenols extract were calculated: $0.47 \mu \mathrm{g} / \mathrm{mL}$, for superoxide $\left(\mathrm{O}_{2}{ }^{-}\right), 0.20 \mu \mathrm{g} / \mathrm{mL}$, for hydoxyl $\left({ }^{\circ} \mathrm{OH}\right), 0.21 \mu \mathrm{g} / \mathrm{mL}$, for hydrogen peroxide $\left(\mathrm{H}_{2} \mathrm{O}_{2}\right)$. Thus apple polyphenols extract exerted an excellent antioxidant activity towards reactive oxygen species (ROS) and more than that of ascorbic acid. The antioxidant effect of apple polyphenols extract on $\mathrm{H}_{2} \mathrm{O}_{2}$ is much better than $\mathrm{O}_{2}{ }^{-}$, but is equal to ${ }^{\circ} \mathrm{OH}$. This suggests that apple polyphenols is an excellent natural antioxidant.

Key Words: Antioxidation, Apple polyphenols, Flow injection chemiluminescence.

\section{INTRODUCTION}

Many reports suggest that regular intake of fruits and vegetables reduces oxidative stress and helps prevent coronary heart disease and stroke $e^{1,2}$. This effect may be partly attributable to antioxidant vitamins and phytochemicals present in fruits and vegetables. Interestingly, several studies also have shown a correlation between increased content of flavonoids in the diet and decreased risk of coronary heart disease ${ }^{3-5}$ and stroke ${ }^{6}$.

Apple is one of the sources of flavonoids in our diet. Apple contain as much as $2 \mathrm{~g}$ of phenols per kilogram wet weight or ca. $400 \mathrm{mg}$ total phenols per apple ${ }^{7}$. The main classes of polyphenols in apples are flavonoids and chlorogenic acid. The beneficial effects of apple consumption have been attributed partly to the phenolic content of the fruit and its associated antioxidant activity.

To evaluate the potential antioxidant effects of substances, many in vitro procedures are employed ${ }^{8-10}$. In the present study, we evaluate the antioxidative effect of apple polyphenols extract by using a flow injection analysis method, which is a fast, accurate system for monitoring chemiluminescence reactions induced by reactive oxygen species $(\mathrm{ROS})^{11}$. The ascorbic acid was used to positive control.

\section{EXPERIMENTAL}

Luminol was purchased from Sigma. Folin Ciocalteau's reagent was purchased from Beijing Solarbio Science and
Technology CO., Ltd. Yantai fuji apple was obtained from the local market. Water was prepared with doubly distilled. Other chemicals were of analytical-reagent grade and were used as supplied unless otherwise stated.

Buffer solutions, pyrogallol solution, potassium ferrocyanide solution, luminol solution and $\mathrm{H}_{2} \mathrm{O}_{2}$ solution, were prepared weekly and stored at $-4{ }^{\circ} \mathrm{C}$. Prior to use they were allowed to reached room temperature. And all luminol solutions were protected from light by a foil wrapper. All the antioxidants solutions were freshly prepared and diluted in doubly distilled water.

Superoxide radicals were generated by the autoxidation of pyrogallol. The concentration of the radicals was not known and is represented by the concentrations of pyrogallol used to generate them.

Hydroxyl radicals were generated by Fenton reaction. The concentration of the radicals was not known and is represented by the concentrations of potassium ferrocyanide and $\mathrm{KH}_{2} \mathrm{PO}_{4}$ - $\mathrm{NaOH}$ buffer ( $\mathrm{pH}$ 7.20) used to generate them.

Hydrogen peroxide was prepared daily by serial dilution of hydrogen peroxide and protected from light by a foil wrapper.

All the chemiluminescence measurements were carried out on the ultra weak luminescence analyzer (IFFM-D, Remex Electronic Institute Limited Co., Xi'an, China) equipped with an eight-channel rotary injection valve and two peristaltic pumps. The chemiluminescence signal in the flow cell was 
detected with the photomultiplier tube and recorded by computer employing an IFFL-D flow-injection chemiluminescence analysis software system (Xi'an Remex Electronic equipment Corporate, Xi'an, China).

Procedures: Preliminary tests were carried out with the aid of different flow assemblies to select the optimal manifold configuration. The assembly in Fig. 1 was selected as the one producing the best compromise between peak height and the peak shape. According to this configuration, the oxidant stream was merged with a water carrier immediately and the combined flow was merged with a luminol/buffer reagent immediately before the flow cell. Consequently, a constant chemiluminescence signal was continuously registered when only water was flowing on the $S$ channel [maximum intensity $\left(I_{\max }\right)$ ]. And when the antioxidant was injected into $S$ channel, the inhibition on the chemiluminescence emission signal [minimum intensity $\left(\mathrm{I}_{\min }\right)$ ] was registered. In order to obtain good stability, the instruments were run for at least 10 min before the first measurement. Experimental parameters were set as: injected sample volume, $50 \mu \mathrm{L}$; reaction tube volume, $90 \mathrm{~mL}$ (0.80 $\mathrm{mm}$ id); sampling and injection time, 15 and $15 \mathrm{~s}$, respectively; rotating speed of pump, $40 \mathrm{round} / \mathrm{min}$ and the flow rates of carrier, sample, reagent were all $2.88 \mathrm{~mL} / \mathrm{min}$.

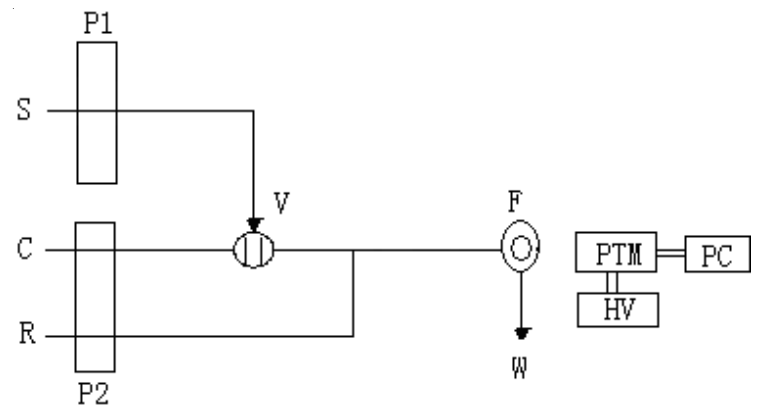

Fig. 1. Diagram of the flow system used in the experiments. S, sample (antioxidant or water ); C,oxidant; R, luminol; P, Peristaltic pump; $\mathrm{V}$, injection valve; F, chemiluminescence flow cell; PMT, photomultiplier tube; HV, negative high-voltage supply; PC, computer; W, waste solution

The chemiluminescence is measured as the photomultiplier output in millivolt. The effects of antioxidants were measured by the depression of the signal from its uninhibited level and were expressed as a percentage attenuation of the CLmax due to the antioxidant. By plotting the chemiluminescence intensity against the time, the maximum and minimum intensity were determined and the percentage of inhibition was determined in each case using the following equation:

$$
\text { Inhibition }(\%)=\left[\frac{\left(I_{\max }-I_{\min }\right)}{I_{\max }}\right] \times 100 \%
$$

$\mathrm{IC}_{50}$ values (which represents the amount of sample that produced a chemiluminescence inhibition of $50 \%$ ) were calculated by using nonlinear regression analysis in computer program.

Results are the mean values of three replicates of the same sample. Statistical analysis was performed using analysis of variance.

Extraction procedure: The flesh and skin of Fuji apple was frozen in liquid nitrogen and completely chopped in a blender. Ten gram of powder was extracted with $30 \mathrm{~mL}$ of acetone, sonicated for $5 \mathrm{~min}$ and centrifuged for $10 \mathrm{~min}$. The resudial powder was reextracted twice with $30 \mathrm{~mL}$ of $70 \%$ aqueous acetone following the above procedure. The three aqueous acetone fractions were pooled and subsequently extracted with $140 \mathrm{~mL}$ of chloroform. After centrifugation (20 $\mathrm{min}$ ), the mixture was partitioned in a separator funnel. The chloroform fraction was discarded and the aqueous acetone fraction was centrifuged for $10 \mathrm{~min}$ and evaporated. The residue was completely dissolved in water to a final volume of $50 \mathrm{~mL}$.

Total phenol content of apple extracts: Total phenol content of apple extracts was determined using the FolinCiocalteu technique ${ }^{12}$. Briefly, a $50 \mu \mathrm{L}$ aliquot of apple extracts was assayed with $250 \mu \mathrm{L}$ Folin reagent and $500 \mu \mathrm{L}$ sodium carbonate $(20 \%, \mathrm{w}: \mathrm{v})$. The mixture was vortexed and diluted with water to a final volume of $5 \mathrm{~mL}$. After incubation for $0.5 \mathrm{~h}$ at room temperature, the absorbance was read at 700 $\mathrm{nm}$ and total phenols in the apple extracts were expressed as gallic acid equivalents, using a standard curve of a freshly prepared gallic acid solution. And the total phenol content of apple extracts was $1.02 \mathrm{~g} / \mathrm{kg}$ wet weight.

\section{RESULTS AND DISCUSSION}

Superoxide: We obtained a continuous chemiluminescence signal from $0.25 \mathrm{mmol} / \mathrm{L}$ pyrogallol in $1.0 \mathrm{mmol} / \mathrm{L}$ hydrochloric acid, $0.40 \mathrm{mmol} / \mathrm{L}$ luminol in $0.10 \mathrm{~mol} / \mathrm{L}$ carbonate buffer at pH 10. Fig. 2 shows a typical chart recorder trace of this and the effect of a sequence of injections of water and $0.20 \mu \mathrm{g} / \mathrm{mL}$ apple polyphenols extract. Chemiluminescence was inhibited by the apple polyphenols extract as shown in Fig. 3. Curves in Fig. 3 were used to determine the $\mathrm{IC}_{50}$. Low values of $\mathrm{IC}_{50}$ implied higher antioxidant capacity. The $\mathrm{IC}_{50}$ value were 0.47 and $1.50 \mu \mathrm{g} / \mathrm{mL}$ for apple polyphenols and ascorbic acid (Table-1). Thus the antioxidant potency order is apple polyphenols $>$ ascorbic acid.

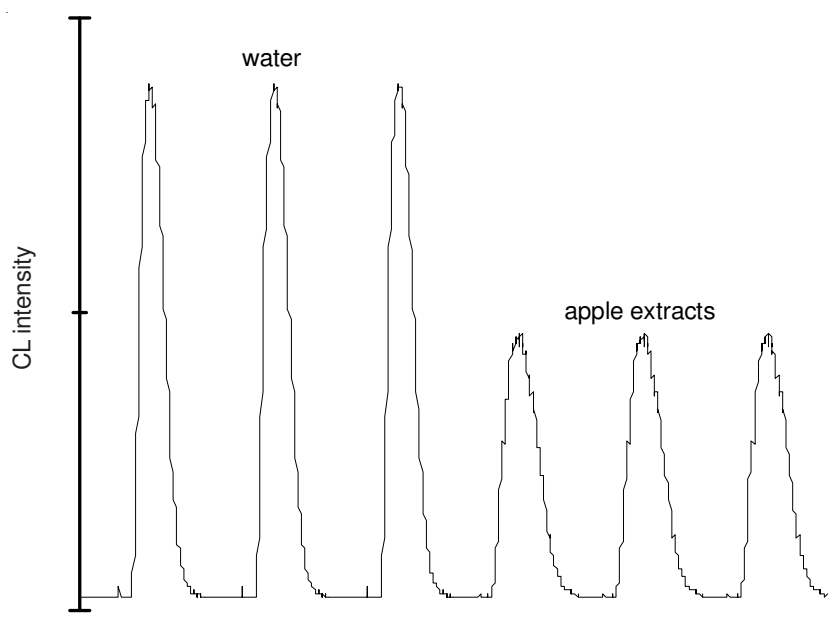

Fig. 2. Chart recorder trace of the signal from $0.25 \mathrm{mmol} / \mathrm{L}$ pyrogallol and $0.40 \mathrm{mmol} / \mathrm{L}$ luminol showing the effect of a sequence of injections of (right to left) water and apple polyphenols extract at $0.20 \mu \mathrm{g} /$ $\mathrm{mL}$, repeating three times of the same sample

Hydroxyl radical: A continuous chemiluminescence signal was given by $0.26 \mathrm{mmol} / \mathrm{L}$ potassium ferrocyanide, 0.10 


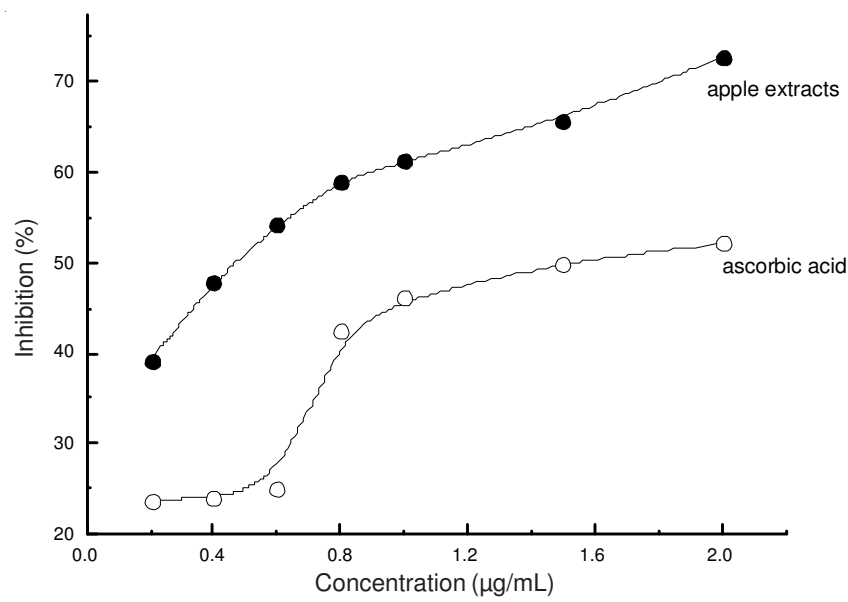

Fig. 3. Inhibition of superoxide-luminol chemiluminescence by apple polyphenols and ascorbic acid at the stated concentrations. LSD at $p<0.05$

$\mathrm{mmol} / \mathrm{L}$ luminol and $0.20 \%$ hydrogen peroxide which were prepared by $\mathrm{KH}_{2} \mathrm{PO}_{4}-\mathrm{NaOH}$ buffer at $\mathrm{pH} 7.20$.

Ferrous iron-induced chemiluminescence was inhibited by apple polyphenols extraction and ascorbic acid in a concentration-dependent manner, as shown in Fig. 4. The $\mathrm{IC}_{50}$ value were 0.20 and $0.54 \mu \mathrm{g} / \mathrm{mL}$ for apple polyphenols and ascorbic acid (Table-1). And the potency order is apple polyphenols $>$ ascorbic acid.

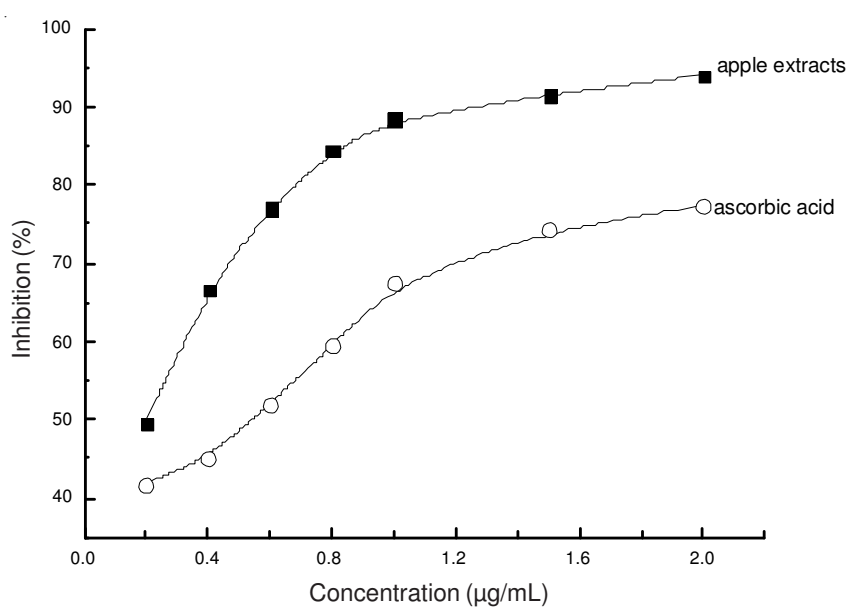

Fig. 4. Inhibition of hydroxyl radical-luminol chemiluminescence by apple polyphenols extract and ascorbic acid at the stated concentrations. LSD at $p<0.05$

\begin{tabular}{|c|c|c|c|}
\hline \multicolumn{4}{|c|}{$\begin{array}{c}\text { TABLE-1 } \\
\text { IC }_{50}(\mu \mathrm{g} / \mathrm{mL}) \text { VALUES OF THE EFFECT OF } \\
\text { ANTIOXIDANTS ON VARIOUS OXIDANTS }\end{array}$} \\
\hline Antioxidants & $\mathrm{O}_{2}^{-\bullet}$ & ${ }^{\circ} \mathrm{OH}$ & $\mathrm{H}_{2} \mathrm{O}_{2}$ \\
\hline Ascorbic acid & 1.50 & 0.54 & 1.18 \\
\hline Apple polyphenols extraction & 0.47 & 0.20 & 0.21 \\
\hline
\end{tabular}

Hydrogen peroxide: We obtained a continuous chemiluminescence signal from $0.20 \% \mathrm{H}_{2} \mathrm{O}_{2}$ and $0.20 \mathrm{mmol} / \mathrm{L}$ luminol in $0.10 \mathrm{~mol} / \mathrm{L}$ carbonate buffer at $\mathrm{pH}$ 9.60. The $\mathrm{H}_{2} \mathrm{O}_{2}$-dependent chemiluminescence signal was inhibited by either apple polyphenols or ascorbic acid, as shown in Fig. 5. The results show that apple polyphenols scavenges $\mathrm{H}_{2} \mathrm{O}_{2}$ more effectively than ascorbic acid. The antioxidant potency order is apple polyphenols $>$ ascorbic acid. The $\mathrm{IC}_{50}$ value were 0.21 and

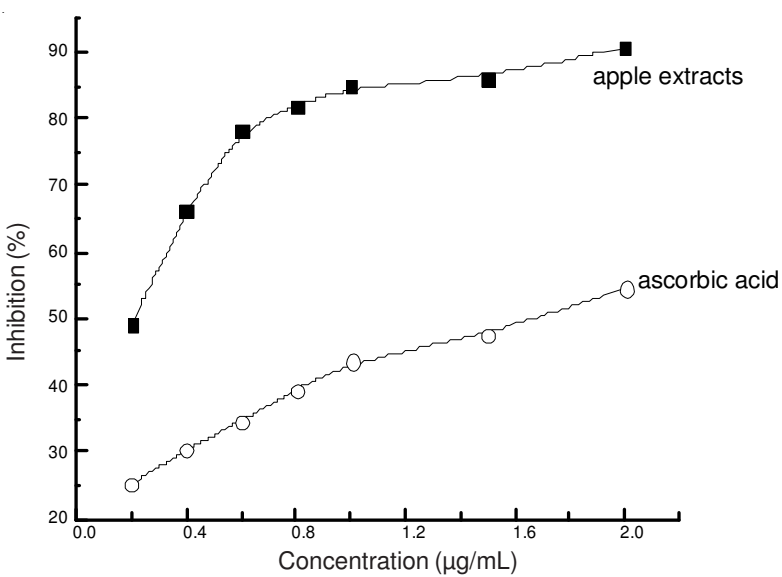

Fig. 5. Inhibition of hydrogen peroxide-luminol chemiluminescence by apple polyphenols extract and ascorbic acid at the stated concentrations. LSD at $p<0.05$

$1.18 \mu \mathrm{g} / \mathrm{mL}$ for apple polyphenols and ascorbic acid (Table-1).

The above results demonstrate that apple polyphenols extract can inhibit and scavenge the ROS such as $\mathrm{O}_{2}^{-\bullet},{ }^{\bullet} \mathrm{OH}$ and $\mathrm{H}_{2} \mathrm{O}_{2}$ effectively and it exhibited greater scavenging activity than ascorbic acid. This suggests that apple polyphenols is an excellent natural antioxidant.

In this study, the antioxidant activity of apple polyphenols extract has been demonstrated by their inhibition of free radicalinduced luminol chemiluminescence. A mechanism for the chemiluminescence of luminol has been proposed ${ }^{13,14}$. In alkaline aqueous solutions, luminol $\left(\mathrm{LH}_{2}\right)$ exists as monoanions $\left(\mathrm{LH}^{-}\right)$, when it lost one electron:

$$
\mathrm{LH}^{-}-\mathrm{e}^{-} \rightarrow \mathrm{L}^{\bullet-}+\mathrm{H}^{+}, \mathrm{L}^{\bullet-}+\mathrm{H}^{+}+\mathrm{O}_{2}^{--} \rightarrow \mathrm{LHO}_{2}^{-}
$$

when it lost two electrons:

$$
\mathrm{LH}^{-}-2 \mathrm{e}^{-} \rightarrow \mathrm{L}+\mathrm{H}^{+}, \mathrm{L}+\mathrm{HO}_{2}^{-} \rightarrow \mathrm{LHO}_{2}^{-}
$$

$\mathrm{LHO}_{2}^{-}$rearranges to a transient endoperoxide, which decomposes to give light emission and products, an aminophthalate and $\mathrm{N}_{2}$. (1) and (2) were all used in our experiments:

$$
\begin{aligned}
& \mathrm{H}_{2} \mathrm{O}_{2}+2 \mathrm{e}^{-} \rightarrow 2 \mathrm{HO}^{-} ; \mathrm{HO}^{\bullet}+\mathrm{e}^{-} \rightarrow \mathrm{HO}^{-} ; \\
& \mathrm{O}_{2}{ }^{--}+\mathrm{H}^{+}+\mathrm{e}^{-} \rightarrow \mathrm{HO}_{2}^{-} ; \mathrm{O}_{2}+\mathrm{e}^{-} \rightarrow \mathrm{O}_{2}{ }^{\circ-}
\end{aligned}
$$

Many reports have been shown that the antioxidant potential of phenolic compounds was depended on both the number of hydroxyl groups and their position on the aromatic ring. The main classes of polyphenols in apples are flavonoids, such as flavonols (quercetin, asglycosides), flavanols ([-]epicatechin, [+]-catechin and their oligomers, procyanidins) and anthocyanins, as well as other phenolic compounds, such as chlorogenic acid, which are all polyhydroxy substances. The phenolic hydroxyl group is easy to ionize by the role of electron delocalization on the aromatic ring and become a good hydrogen donor. The apple polyphenols contains a large number of such hydrogen donor groups, which has a strong ability to provide the hydrogen protons and enables highly oxidizing free radicals such as $\mathrm{O}_{2}{ }^{-}, \mathrm{HO}^{\bullet}, \mathrm{HO}_{2}{ }^{\bullet}$ to restore and then to terminate the radical chain reaction of free radicals as mentioned above. In addition, apple polyphenols extract is a complex mixture of various phenolic compounds, therefore we can not neglect the interaction between a single substance, but which is synergistic or antagonistic effects further studies are needed. 


\section{ACKNOWLEDGEMENTS}

This work was supported by the Ministry of Agriculture: Modern Industry Technology System of Apples-Postharvest Handling of Apples (Nycytx-08) and Tai'an Technology Development Program (20123071).

\section{REFERENCES}

1. A.J. Verlangieri, J.C. Kapeghian, S. El-Dean and M. Bush, Med. Hypoth., 16, 7 (1985).

2. K.J. Joshipura, F.B. Hu, J.E. Manson, M.J. Stampfer, E.B. Rimm, F.E. Speizer, G. Colditz, A. Ascherio, B. Rosner, D. Spiegelman and W.C. Willett, Ann. Intern. Med., 134, 1106 (2001).

3. M.G. Hertog, E.J. Feskens, P.C. Hollman, M.B. Katan and D. Kromhout, Lancet, 342, 1007 (1993).

4. M.G. Hertog, D. Kromhout, C. Aravanis, H. Blackburn, R. Buzina, F. Fidanza, S. Giampaoli, A. Jansen, A. Menotti, S. Nedeljkovic, M. Pekkarinen, B.S. Simic, H. Toshima, E.J.M. Feskens, P.C.H. Hollman, and M.B. Katan, Arch. Intern. Med., 155, 381 (1995).
5. P. Knekt, R. Jarvinen, A. Reunanen and J. Maatela, Br. Med. J., 312, 478 (1996).

6. S.O. Keli, M.G. Hertog, E.J. Feskens and D. Kromhout, Arch. Int. Med., 156, 637 (1996).

7. A. Scalbert and G. Williamson, J. Nutr., 130, 2073S (2000).

8. B.N. Singh, B.R. Singh, R.L. Singh, D. Prakash, D.P. Singh, B.K. Sarma, G. Upadhyay and H.B. Singh, Food Chem. Toxicol., 47, 1161 (2009).

9. J.M. Landete, J.A. Curiel, H. Rodríguez, B. de las Rivas and R. Muñoz, Food Chem., 107, 320 (2008).

10. D. Prakash, B.N. Singh and G. Upadhyay, Food Chem., 102, 1389 (2007).

11. M. Sariahmetoglu, R.A. Wheatley, I. Cakici, I. Kanzik and A. Townshend, Anal. Lett., 36, 749 (2003).

12. V.L. Singleton and J.A. Rossi, Am. J. Enol.Vitic., 16, 144 (1965).

13. D.F. Roswell and E.H. White, In ed.: M.A. DeLuca, Bioluminescence and Chemiluminescence, In: Methods in Enzymology, New York, Vol. 57, p. 409 (1978)

14. J. Lind, G. Merenyi and T.E. Eriksen, J. Am. Chem. Soc., 105, 7655 (1983). 